on the brows of the growing phalanx of "social gerontologists".

Although these proceedings are not the last word on age studies (the meeting was held four years ago and much has happened since that time) they make an excellent, authoritative and thoughtful review of the field. The papers by Hachinski and Obrist, by Scheibel and Scheibel, and by Ordy, on different aspects of brain ageing, merit reprinting where physicians will see them.

Alex Comfort is Consultant in Geriatric Psychiatry to the Veterans'Administration, Los Angeles, and an Adjunct Professor at the University of California, Los Angeles.

\section{Search for solutions}

\section{Barbara W. Low}

Structural Studies on Molecules of Biological Interest: A Volume in Honour of Dorothy Hodgkin. Edited by G. Dodson, J.P. Glusker, and D. Sayre. Pp.610. ISBN 0-19-855362-5. (Oxford University Press: 1981.) £39, $\$ 98$.

THE arts and pleasures of praise, in writing, as in reading, may be direct or oblique. This Festschrift, written in honour of Dorothy Hodgkin, whose seventieth birthday it celebrates, abundantly manifests these several purposes with grace and rich diversity.

There are contributions from friends, colleagues and former students. Among these latter, Dennis Riley evokes the remarkable limitations of the early laboratory in the University Museum at Oxford (almost a gaslight era), and recalls their essential irrelevance. But he remembers, as we all remember, Dorothy Hodgkin's unique gift for proposing exciting problems without obvious means of solution and the exhilaration and triumph of their solution - learning to swim by being dropped in the deep end.

The section on insulin might be the transactions of a symposium, with all the original sense of convivial atmosphere and stimulating discourse. It provides a brief but fascinating account both of early studies and of those which have followed the determination of the insulin structure in Dorothy Hodgkin's laboratory. There is a continuity of theme in the contributions from different disciplines, for all are built around the concept of structure and function. No where is this more evident than in the account by Zhang You-Shang of the Shanghai Insulin Research Group. Zhang describes the investigation, using semi-synthetic methods, of insulin activity associated with modification of the C-terminal region of the $B$ chain. The activity of D-Ala B23 deshexapeptide insulin is neatly accounted for in terms of the Ramachandran angles of B23 Gly (normal residue) which lie, in the Ramachandran angle plot, within the permitted region for the $\mathrm{D}$-configuration.

From the contribution of the Peking Insulin Research (Structure) Group, we learn that $\mathrm{X}$-ray crystal structure and solution studies of the B chain C-terminal despenta- and desheptapeptide insulins are in progress, with their promise of a closer appreciation of structure/function relationships and the relationship between binding site and active site. Mercola and Wollmer provide an illuminating example of the enhanced understanding of solution phenomena which the high-resolution study of a protein may bring. This section also includes a nice discussion by Sakabe and colleagues of hydrogen bonding in the insulin structure at $1.2 \AA$ resolution. These contributions abord in different ways the fundamental question of intrinsic molecular flexibility or rigidity, particularly at the binding site. I also enjoyed the discussion of Falkmer and Emdem on insulin evolution and Steiner's contribution on insulin precursors.

I have chosen to write of this section in the greatest detail because it represents not only the continuity of Dorothy Hodgkin's interests, but also a continuity of theme and focus. Crystallographers will especially enjoy the methods section, which includes a discussion by Bentley and Mason of the neutron diffraction study of monoclinic lysozyme and a contribution by Isaacs on fast-Fourier least-squares refinement. The more general section on protein structure includes an account by Harrison - "Approaches to the Structure and Function of Ferritin" - a history of crystal structure studies of the virus-like iron storage protein apoferritin. She concludes this provocative contribution with a reference to the isolation of a ferritin-like protein from Azotobacter vinelandii and from $E$. coli. Vainshtein also spans the range of common function by describing the structure of leghaemoglobin (from Lupinus nodule extracts) and comparing it with the functionally-related myoglobin.

There are also rewards elsewhere in the book. The contributions by Glusker on the vitamin $\mathrm{B}_{12}$ work and by Harding on the study of gramicidin S structure both provide a lively sense of the experimentalist tackling difficult problems by persistent frontal attack and by flanking approaches, reconsidering constantly as all evidence is re-evaluated. Thus difficulties may be approached almost by stealth - the coaxing of a problem to its solution.

There are many other stimulating and pleasing contributions. But to choose was here a regrettable necessity. The editors deserve our warmest congratulations and gratitude.

Barbara W. Low is Professor of Biochemistry at Columbia University. She worked under Dorothy Hodgkin's supervision and her doctoral thesis described the X-ray crystal determination in three dimensions of potassium and rubidium penicillin.

\section{Medicines worldwide}

\section{John Butterfield}

Pharmaceuticals and Health Policy: International Perspectives on Provisions and Control of Medicines. Edited by R. Blum et al. Pp.272. ISBN 0-7099-0608-0. (Croom Helm/Holmes \& Meier: 1981.) $£ 17.95, \$ 37.50$.

THE provision of medicines in the modern world is a complex process. It begins with the research stage; proceeds through toxicity testing and government-regulated clinical trials, drug licensing and registration; then passes into the distribution phase, which includes promotion by the manufacturers, dispensing by pharmacists and, in the case of certain medicines, prescription by the medical profession; finally it ends with consumption by patients. The beliefs and knowledge of the latter may critically affect patterns of actual drug usage in the home, a fact too often ignored by the professionals who direct the previous stages.

The authors of Pharmaceuticals and Health Policy collectively espouse the view that improved health care depends, in part, on the improved supply of medicines. To this end they present information about each of the key stages of the provision process and outline the various, sometimes conflicting, interests of the actors in the drama. Wisely, then, the editors have combined the skills of individuals from many disciplines - including medicine, psychology, administration, pharmacology, epidemiology, economics and sociology - and the result is an impressive amalgam of different viewpoints.

In tackling such a broad subject, the volume inevitably has its weaknesses. For example, despite the fact that readers are urged to identify themselves as "friends of research and discovery", little attempt is made to discuss the alternative forms of research management and funding which a community might adopt. Under what conditions is marked-funded, industrial research superior to state-funded, academic research? What acceptable or unacceptable "disbenefits" may be associated with each of these different modes of research support? Why have the international pharmaceutical houses been the source of so much of the pharmacological innovation of recent decades?

Similarly, despite a long essay on the individual use of medicines, no clear image emerges as to how the authors envisage consumers might be influenced to create more appropriate and productive behaviour in the field of drug usage. Personally, I would have preferred to see a more specific consideration of the needs and problems of that section of the population that conventional health education cannot reach, that is the poorer people the people for whom education may be an anathema, who may be mentally less able 